CLINICAL STUDY

\title{
Altered fasting and postprandial plasma ghrelin levels in patients with liver failure are normalized after liver transplantation
}

\author{
Maria Teresa Diz-Lois ${ }^{1}$, Jesús Garcia-Buela ${ }^{4}$, Francisco Suarez ${ }^{1}$, Susana Sangiao-Alvarellos ${ }^{3,5}$, Ovidio Vidal ${ }^{2}$ \\ and Fernando Cordido ${ }^{2,3,5}$ \\ Departments of ${ }^{1}$ Gastroenterology, ${ }^{2}$ Endocrinology, ${ }^{3}$ Investigation, ${ }^{4}$ Laboratory, University Hospital A Coruña. Xubias de Arriba 84,15006 A Coruña, \\ Spain and ${ }^{5}$ Department of Medicine, University of A Coruña, 15006 A Coruña, Spain
}

(Correspondence should be addressed to F Cordido at Department of Endocrinology; Email: fernando.cordido.carballido@sergas.es)

\begin{abstract}
Context: Anorexia is a problem of paramount importance in patients with advanced liver failure. Ghrelin has important actions on feeding and weight homeostasis. Experimental data exist, which suggest that ghrelin could protect hepatic tissue. Both fasting and post-oral glucose tolerance test (OGTT) ghrelin concentrations are controversial in liver cirrhosis and are unknown after liver transplantation.

Objective: Our aim was to study fasting ghrelin concentrations and their response to an OGTT in liver failure patients before and after liver transplantation.

Design and methods: We included 21 patients with severe liver failure studied before (pretransplantation, PreT) and 6 months after liver transplantation (posttransplantation, PostT), and 10 age- and body mass index-matched healthy or overweight subjects as the control group (Cont). After an overnight fast, $75 \mathrm{~g}$ of oral glucose were administered; glucose, insulin, and ghrelin were obtained at baseline and at times 30, 60, 90, and $120 \mathrm{~min}$.

Results: Fasting ghrelin (median and range, pg/ml) levels were lower in PreT: 539 (309-1262) than in Cont: 643 (523-2163), $P=0.045$. Fasting ghrelin levels increased after liver transplantation, 539 (309-1262) vs 910 (426-3305), for PreT and PostT respectively, $P=0.001$. The area under the curve (AUC) of ghrelin (pg/ml min) was lower in PreT: 63900 (37 260-148 410) than in Cont: 76560 (56 160-206 385), $P=0.027$. The AUC of ghrelin increased in PostT, 63900 (37 260-148 410) vs 107595 (59 535-357 465), for PreT and PostT respectively, $P=0.001$. Fasting levels and the AUC of ghrelin were similar in PosT and Cont.

Conclusions: Decreased fasting and post-OGTT ghrelin levels in liver failure patients were normalized after liver transplantation.
\end{abstract}

European Journal of Endocrinology 163 609-616

\section{Introduction}

Malnutrition is common in patients with liver failure, with a reported prevalence as high as $80 \%$ depending on the severity of liver disease $(1,2)$. The mechanisms of malnutrition in cirrhosis are not fully understood. Anorexia is a problem of paramount importance in patients with advanced cirrhosis, contributing to malnutrition. In turn, malnutrition is a risk factor for the development of life-threatening complications and increased mortality $(3,4)$.

Ghrelin is a 28-amino acid peptide, predominantly produced by the stomach $(5,6)$. Apart from stimulating $\mathrm{GH}$ secretion, ghrelin has other endocrine and nonendocrine actions (7). Different studies suggest the importance of ghrelin in feeding and weight homeostasis (8-13). Circulating plasma ghrelin increases before a meal and decreases following the consumption of nutrients and after an oral glucose tolerance test (OGTT) (14-16). There are two major circulating forms of ghrelin: acylated and des-acyl ghrelin (7). Acylated ghrelin has proved to be highly relevant in the development of metabolic disturbances, although total ghrelin has a well-established correlation with metabolic disturbances. In fact, most of the leading studies on the correlation between metabolic disturbances and ghrelin have focused on the estimation of total ghrelin $(10,11,13-15)$, and there are concerns about the specificity of available acylghrelin assays (17). We focused on measuring total ghrelin, with the aim of comparing our data with the discrepant total ghrelin levels that have been found in hepatic failure patients in different studies (18-24).

Experimental data exists that suggests that ghrelin could protect hepatic tissue. A ghrelin analog, GHRP-2, 
has a protective effect on the liver in rats, which seems to be mediated by insulin-like growth factor 1 (IGF1), tumour necrosis factor $\alpha$ (TNF $\alpha$ ), and nitric oxide (25). Ghrelin alleviates biliary obstruction-induced chronic hepatic injury in rats (26). Ghrelin treatment ameliorates pancreaticobiliary inflammation and remote organ injury in rats (27). Taking all these data into account, decreased ghrelin levels could be a contributing factor for the deterioration of liver function in cirrhosis.

Basal concentrations of ghrelin have been reported to be deranged in liver cirrhosis, but the results are controversial. Normal, increased, and decreased ghrelin levels have been found in hepatic failure patients $(18,19-23)$. We have previously found significantly decreased fasting and post-OGTT plasma ghrelin levels in patients with liver failure who were candidates for transplantation when compared with control subjects (Cont) (24).

In order to clarify the controversy over ghrelin levels in hepatic failure, our aim was to study fasting circulating ghrelin levels and their response to an OGTT in liver failure patients before and after liver transplantation.

\section{Patients and methods}

\section{Patients}

We included 21 patients (14 males and 7 females) with liver failure prior to liver transplantation, with a median (range) age of 56.0 (23-66) years and a median (range) body mass index (BMI) of $27.5(18.6-33.7) \mathrm{kg} / \mathrm{m}^{2}$. As a Cont group, ten age- and BMI-matched healthy or overweight subjects (six males and four females) were included, selected from a pool of volunteers available to our unit, were included, with a median (range) age of 58.5 (54-65) years and a median (range) BMI of 26.4 (20-29.7) $\mathrm{kg} / \mathrm{m}^{2}$. The diagnosis of liver cirrhosis was either established histologically, or based on its clinical, laboratory, endoscopic, or imaging features, or both. The severity of liver disease was assessed according to Child-Pugh and the model for end-stage liver disease (MELD) scores. The causes of liver cirrhosis were the following: in ten patients, alcohol was the primary cause of the disease; in four patients, the cause was viral hepatitis (hepatitis B in two cases; hepatitis C in two cases); in five patients, the cause was hepatocellular carcinoma; in one patient the cause was primary biliary cirrhosis; in one patient, the cause was primary sclerosing cholagitis. At the time of the study, the patients with alcoholic liver disease had abstained from alcohol for 6 months or more. All cases had routine biochemical investigation, an ultrasound scan of the liver, and a gastrointestinal endoscopy. Among the patients with liver failure prior to liver transplantation, there were six patients who had been diagnosed with diabetes mellitus prior to the study protocol, who were being treated with dietetic therapy. All patients were ambulatory. Liver transplantation was performed according to the well-established clinical protocol in our hospital, with all the patients receiving a liver transplant from a cadaver donor. All patients received identical intraoperative and postoperative care. Immunosuppression was performed with prednisone and a calcineurin inhibitor drug (cyclosporine or tacrolimus).

\section{Study procedure}

Between 0830 and $0900 \mathrm{~h}$, after an overnight fast and while seated, a peripheral venous line was obtained. Fifteen minutes later, $75 \mathrm{~g}$ of oral glucose was administered. We obtained blood samples for glucose, insulin, and ghrelin at baseline (fasting), and then at 30, 60, 90, and $120 \mathrm{~min}$. Basal levels of GH and IGF1 were also measured. All blood samples were immediately centrifuged, separated, and frozen at $-80^{\circ} \mathrm{C}$. Samples destined to be used for the determination of plasma ghrelin were specifically retrieved in chilled tubes containing aprotinin and EDTA-Na, and then immediately centrifuged at $4{ }^{\circ} \mathrm{C}$, separated to aliquots, and frozen at $-80{ }^{\circ} \mathrm{C}$. All the studies were carried out in accordance with the Declaration of Helsinki. The study protocol was approved by our centre's ethical committee, and written informed consent was obtained from all patients and controls. The OGTT was carried out prior to liver transplantation and 6 months after. Fasting levels were obtained prior to liver transplantation and $1,3,6$, and 12 months after.

\section{Assays}

Plasma glucose $(\mathrm{mg} / \mathrm{dl})$ was measured with an automatic glucose oxidase method (Roche Diagnostics). Insulin $(\mu \mathrm{U} / \mathrm{ml})$ was measured with a solid-phase twosite chemiluminescent immunometric assay (Immulite 2000 Insulin, DPC, Los Angeles, CA, USA) and with intrassay coefficients of variation $(\mathrm{CV})$ of $5.5,3.3$, and $3.7 \%$ for low, medium, and high plasma insulin levels respectively. Serum GH $(\mu \mathrm{g} / \mathrm{l})$ was measured by a solidphase, two-site chemiluminescent enzyme immunometric assay (Immulite, EURO/DPC) with a sensitivity of $0.01 \mu \mathrm{g} / \mathrm{l}$ and with intrassay $\mathrm{CV}$ of $5.3,6.0$, and $6.5 \%$ for low, medium, and high plasma $\mathrm{GH}$ levels respectively. IGF1 $(\mathrm{ng} / \mathrm{ml})$ was determined by a chemiluminescence assay (Nichols Institute, San Clemente, CA, USA) and with intrassay CV of $4.8,5.2$, and $4.4 \%$ for low, medium, and high plasma IGF1 levels respectively. Total ghrelin $(\mathrm{pg} / \mathrm{ml})$ was measured by a commercially available RIA (Linco Research Inc., St Charles, MO, USA), specific for total ghrelin, which uses ${ }^{125}$ I-labeled ghrelin tracer and rabbit antighrelin serum with a specificity of $100 \%$, with an intrassay CV of between 4.4 and $10 \%$.

All the samples from a given subject were analyzed in the same assay run. The area under the secretory 
curve (area under the curve, AUC) was calculated by a trapezoidal method. Insulin resistance was calculated on the basis of fasting values of plasma glucose and insulin, according to the homeostasis model assessment (HOMA-IR) method (28) as follows: HOMA-IR = fasting insulin levels $\times$ fasting glucose levels/22.5, where basal insulin levels are in $\mu \mathrm{U} / \mathrm{ml}$, and glucose is in $\mathrm{mmol} / \mathrm{l}$.

\section{Statistical analysis}

The results are presented as median (range). All comparisons were based on univariate, nonparametric tests. Intragroup comparisons were based on Wilcoxon signed rank test. Comparisons between patients and controls were based on Mann-Whitney U test. Numerical correlations were analyzed using Spearman's correlation test. $P$ values $\leq 0.05$ were considered to be significant. For graphical presentation, we use mean values \pm s.e.m. Version 12 of the SPSS software (Chicago, IL, USA) was used for the statistical analysis.

\section{Results}

The basic characteristics of the healthy Cont group and patients are shown in Table 1. The severity of liver disease was (median and range), according to ChildPugh: 9 (5-12) and the MELD: 14 (7-23). Albumin (median and range) was decreased in liver failure patients when compared with the Cont group, 3.0 $(2.6-4.6)$ vs $4.1(3.4-5.3) \mathrm{g} / \mathrm{dl}, P=0.009$.

\section{Fasting serum levels}

The fasting serum levels presented (Table 2) are Cont, pretransplantation (PreT), and 6th month after transplantation (posttransplantation, PostT) values.

Table 1 Basic characteristics of control subjects and liver failure patients pretransplantation (median and range).

\begin{tabular}{lll}
\hline & Controls & Liver failure patients \\
\hline $\begin{array}{l}\text { Male/female } \\
\text { (number) }\end{array}$ & $6 / 4$ & $14 / 7$ \\
Age (years) & $58.5(54-65)$ & $56.0(23-66)$ \\
BMl (kg/m $\left.{ }^{2}\right)$ & $26.4(20-29.7)$ & $27.5(18.6-33.7)$ \\
MELD score & & $14(7-23)$ \\
Child-Pugh score & & $9(5-12)$ \\
Albumin (g/dl) & $4.1(3.4-5.3)$ & $3.0(2.6-4.6)^{\star}$ \\
Bilirubin (mg/dl) & $0.5(0.4-0.9)$ & $2.8(0.5-12.7)^{\star}$ \\
Etiology & & 10 \\
Alcoholic & & 4 \\
Viral & & 5 \\
Hepatocellular & & 1 \\
$\quad$ carcinoma & & 1 \\
PBC & & \\
PSC & & \\
\hline
\end{tabular}

BMI, body mass index; MELD, model for end-stage liver disease PBC, primary biliary cirrhosis; PSC, primary sclerosing cholagitis. ${ }^{*} P<0.01$ between patients and controls.
Fasting glucose and insulin (median and range) were similar in the PreT and in the Cont group, basal glucose 101 (62-177) vs 95 (89-109) mg/dl, P=NS; fasting insulin 8.5 (1.0-159) vs $5.1(2-12) \mu \mathrm{U} / \mathrm{ml}, P=\mathrm{NS}$, for patients and controls respectively. Fasting glucose and insulin (median and range) were similar in the PreT and PostT patients, basal glucose 101 (62-177) vs 98 (71-226) $\mathrm{mg} / \mathrm{dl}, P=\mathrm{NS}$; fasting insulin 8.5 (1.0-159) vs $8.2(3.7-37.3) \mu \mathrm{U} / \mathrm{ml}, P=\mathrm{NS}$, for liver failure patients prior to liver transplantation and after liver transplantation respectively. Fasting insulin levels were higher in the PosT than in the Cont group.

Fasting GH (median and range) levels were higher in PreT than in Cont, 2.7 (0.2-6.9) vs $0.2(0.1-0.9) \mu \mathrm{g} / \mathrm{l}$, $P=0.001$, for PreT and Cont respectively. Fasting GH (median and range) levels were similar in the PreT and PostT group, 2.7 (0.2-6.9) vs $2.0(0.1-8.2) \mu \mathrm{g} / \mathrm{l}, P=\mathrm{NS}$ for the PreT and PostT patients respectively. Fasting IGF1 (median and range) levels were lower in PreT patients than in Cont subjects 32 (25-112) vs 87 (52-102) ng/ml, $P=0.008$, for PreT patients and Cont subjects respectively. Fasting IGF1 levels increased after liver transplantation, 32 (25-112) vs 135 (69-371) ng/ml, $P=0.008$, for the PreT and PostT patients respectively.

Fasting ghrelin (median and range) levels were lower in PreT patients than in Cont, 539 (309-1262) vs 643 (523-2163) pg/ml, $P=0.045$, for PreT patients and Cont respectively. Fasting ghrelin levels increased after liver transplantation, 539 (309-1262) vs 910 (426-3305) pg/ml, $P=0.001$, for the PreT and PostT patients respectively. Fasting ghrelin levels were similar in the PostT patients and Cont group. The results are presented in the figures as mean values \pm s.e.M., for the sake of clarity and to improve the readability. Figure 1 shows fasting serum levels (mean \pm s.e.m.) of ghrelin $(\mathrm{pg} / \mathrm{ml})$ pre-transplantation and 1, 3, 6, and 12 months after liver transplantation. Fasting ghrelin levels increased and normalized after liver transplantation, during all the study period (12 months) after the transplant.

Liver function indices, MELD score and Child-Pugh score, albumin, and bilirubin completely normalized after liver transplantation (Table 2).

\section{Serum levels after oral glucose}

Glucose was higher in PreT patients than in the Cont group after the OGTT. At $120 \mathrm{~min}$ after the OGTT, glucose was higher in PreT patients than in the Cont group, 236 (93-346) vs 95 (57-164) mg/dl, for PreT and Cont respectively, $P=0.001$. Glucose levels at any time point after the OGTT were similar in the PreT and PostT patients (Fig. 2a, mean values \pm s.E.M). Insulin levels were similar in the PreT patients and Cont group. The AUC of insulin was similar in PreT patients and Cont, 4900 (1893-245 700) vs 4107 (2068-12 441) $\mu \mathrm{U} / \mathrm{ml} \mathrm{min}$, for PreT and Cont respectively, $P=\mathrm{NS}$. Insulin levels were higher at time points 90 and 
Table 2 Fasting and post OGTT biochemical and hormonal data (median and range) in Cont, PreT, and 6th month PostT patients.

\begin{tabular}{|c|c|c|c|}
\hline & Cont & PreT & PostT \\
\hline BMI $\left(\mathrm{kg} / \mathrm{m}^{2}\right)$ & $26.4(20-29.7)$ & $27.5(18.6-33.7)$ & $27.0(17.6-36.0)$ \\
\hline Albumin (g/dl) & $4.1(3.4-5.3)^{\dagger}$ & $3.0(2.6-4.6)$ & $4.4(3.9-5.1)^{\S}$ \\
\hline Bilirubin (mg/dl) & $0.5(0.4-0.9)^{\dagger}$ & $2.8(0.5-12.7)$ & $0.8(0.4-2.2)^{\S}$ \\
\hline Fasting glucose & $95(89-109)$ & $101(62-177)$ & $98(71-226)$ \\
\hline Fasting insulin $(\mu \mathrm{Ul} / \mathrm{ml})$ & $5.1(2.0-12.0)$ & $8.5(1-159)$ & $8.2(3.7-37.3)^{\|}$ \\
\hline HOMA & $1.1(0.4-2.7)$ & $2.29(0.15-56.53)$ & $1.9(0.96-30.02)$ \\
\hline $\mathrm{GH}(\mu \mathrm{g} / \mathrm{l})$ & $0.2(0.1-0.9)^{\dagger}$ & $2.7(0.2-6.94)$ & $2(0.1-8.2)$ \\
\hline IGF1 (nq/ml) & $87(52-102)^{\dagger}$ & $32(25-112)$ & $135(69-371)^{\S}$ \\
\hline Fasting ghrelin (pg/ml) & $643(523-2163)^{*}$ & $539(309-1262)$ & $910(426-3305)^{\S}$ \\
\hline Ghrelin after OGTT (pg/ml) & $584(493-1109)^{*}$ & 447 (334-1186) & $860(461-2508)^{\S}$ \\
\hline Nadir ghrelin $(\mathrm{pg} / \mathrm{ml})$ & $567(442-1154)^{*}$ & $444(244-1186)$ & $843(426-2508)^{\S}$ \\
\hline AUC ghrelin (pg/ml min) & $76560(56$ 160-206 385)* & 63900 (37 260-148 410) & $107595(59535-357465)^{\S}$ \\
\hline
\end{tabular}

HOMA, homeostasis model assessment; AUC, area under the secretory curve. Ghrelin after OGTT, 120 min ghrelin after OGTT. ${ }^{*}<<0.05$ between patients PreT and Cont, ${ }^{\dagger} P<0.01$ between patients PreT and Cont. ${ }^{\circledR} P<0.01$ between patients PreT and 6th month Post $T$. ${ }^{\|} P<0.05$ between patients Post $T$ and Cont.

120 min after OGTT in the PreT when compared with the PostT group (Fig. 2b, mean values \pm s.E.M). The AUCs of insulin was higher in the PreT when compared with the PostT group, 4900 (1893-245 700) vs 3752 (1893-24 570) $\mu \mathrm{UI} / \mathrm{ml} \mathrm{min,} \mathrm{for} \mathrm{the} \mathrm{PreT} \mathrm{and} \mathrm{PostT}$ group respectively, $P=0.011$. Figure $2 \mathrm{a}$ and $\mathrm{b}$ show serum glucose and insulin levels (mean values \pm s.E.m.) in Cont subjects, PreT and PostT patients during the OGTT.

Ghrelin levels decreased during the OGTT, and nadir ghrelin levels were lower than fasting total ghrelin levels for PreT patients, Cont and PostT patients; PreT: 539 (309-1262) vs 444 (244-1186) $\mathrm{pg} / \mathrm{ml}$, for fasting and nadir ghrelin respectively, $P=0.001$; Cont: 643 (523-2163) vs $567(442-1154) \mathrm{pg} / \mathrm{ml}$, for fasting and nadir ghrelin respectively, $P=0.008$; PostT: 910 (426-3305) vs 843 (426-2508) pg/ml, for fasting and nadir ghrelin respectively, $P=0.008$. As shown in Fig. 3, the response of post-OGTT ghrelin levels (mean values \pm s.e.m.) in hepatic failure patients was similar to normal subjects, in both groups, PreT and PostT, ghrelin levels decreased during the OGTT.

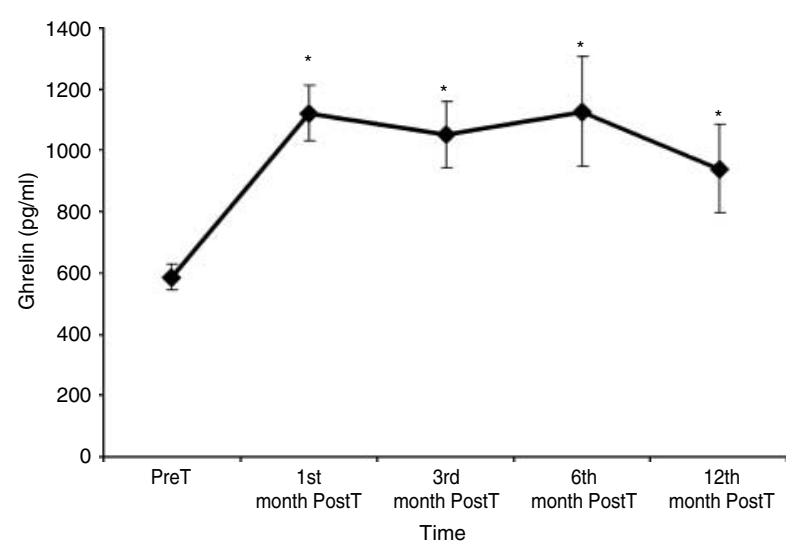

Figure 1 Fasting serum levels (mean \pm s.E.M.) of ghrelin $(\mathrm{pg} / \mathrm{ml})$ PreT and 1, 3, 6, and 12 months post liver transplantation. ${ }^{*} P<0.05$ between PreT and PostT patients at any time point.
Ghrelin was lower in the PreT patients than in the Cont group after the OGTT. The AUCs of total ghrelin were lower in the PreT patients than in the Cont group, 63900 (37 260-148 410) vs 76560 (56 160-206 385) $\mathrm{pg} / \mathrm{ml} \mathrm{min,} \mathrm{for} \mathrm{PreT} \mathrm{and} \mathrm{Cont}$ respectively, $P=0.027$. Post-OGTT ghrelin levels increased in the PostT patients. The AUCs of total ghrelin increased in the PostT, 63900 (37 260-148 410) vs 107595 (59 535-357 465) $\mathrm{pg} / \mathrm{ml} \mathrm{min}$, for the PreT and PostT patients, $P=0.001$. The AUC of total ghrelin was similar in the PostT patients and Cont group. Figure 3 shows serum ghrelin levels (mean values \pm s.E.M.) in the Cont group, PreT and PostT patients during the OGTT. Ghrelin levels were decreased in the PreT patients when compared with the Cont group, along all the time points. In the PostT patients, ghrelin levels increased when compared with the PreT patients, and were similar to the Cont group, along all the time points. Table 2 shows fasting and post-OGTT data (median and range) in the Cont group, PreT and PostT patients.

\section{Correlations}

Although a small number of patients was used for the correlation studies, in the PreT and PostT patients, we analyzed if there was any significant correlation between fasting ghrelin or ghrelin AUC levels or nadir ghrelin and age, BMI, IGF1, fasting glucose, basal GH, fasting insulin, insulin resistance as estimated by HOMA, glucose peak, insulin peak, glucose AUC, and insulin AUC. In the PreT patients, fasting total ghrelin levels negatively correlated with BMI $(r=-0.492$; $P=0.023)$, ghrelin AUC negatively correlated with BMI $(r=-0.440 ; P=0.046)$ and with insulin AUC $(r=-0.526, P=0.014)$, and nadir ghrelin negatively correlated with insulin AUC $(r=-0.562, P=0.008)$. Fasting ghrelin negatively correlated with fasting $\mathrm{GH}$ $(r=-0.500, P=0.029)$ in the 12th month after liver transplantation. We were unable to discover any other significant correlation. 

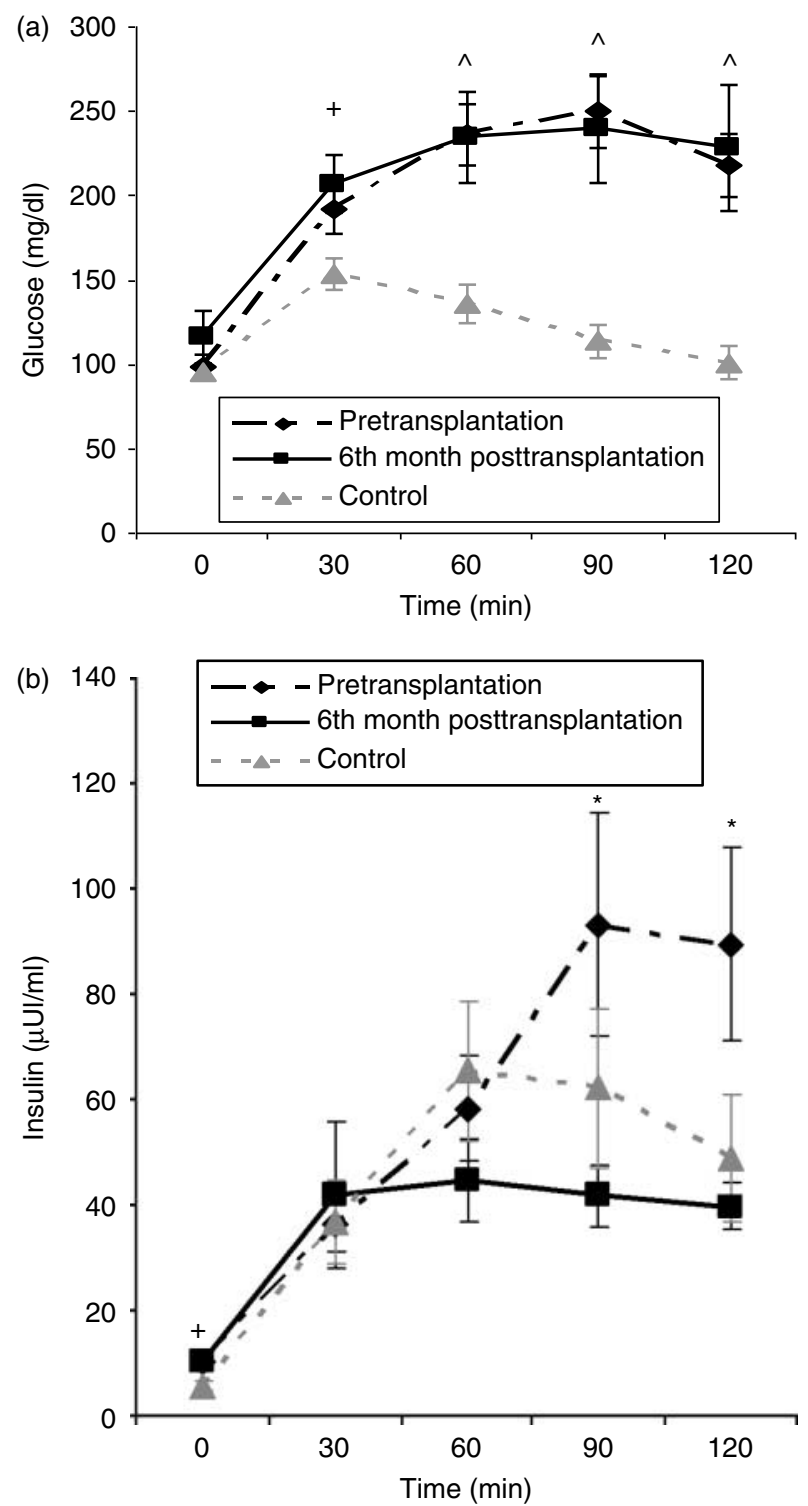

Figure 2 (a) Mean \pm S.E.M. plasma glucose (mg/dl) in controls, liver failure patients pretransplantation, and 6th month posttransplantation during the oral glucose tolerance test. ${ }^{+} P<0.05$ between controls and 6th month posttransplantation patients at that time points. ${ }^{\wedge} P<0.05$ between controls and pretransplantation or 6 th month posttransplantation patients at that time points. (b) Mean \pm S.E.M. serum insulin levels $(\mu \mathrm{Ul} / \mathrm{ml})$ in controls, liver failure patients pretransplantation, and 6th month posttransplantation during the oral glucose tolerance test. ${ }^{+} P<0.05$ between controls and 6th month posttransplantation patients at that time point. ${ }^{*} P<0.05$ between pretransplantation and 6th month posttransplantation patients at that time points.

\section{Discussion}

Fasting total ghrelin levels have been studied in hepatic failure patients, with some studies finding increased ghrelin levels (20, 23). Atavesen et al. (20) found that in cirrhosis, serum ghrelin levels were increased with a corresponding decrease in serum leptin concentrations. The increase in ghrelin was more prominent in Child C cirrhosis, and the level was correlated with TNF $\alpha$. Tacke et al. (23) found that ghrelin was significantly elevated and IGF1 reduced in chronic liver disease patients compared with healthy Cont subjects. IGF1 serum levels inversely correlated with Child's classification. Ghrelin levels were significantly elevated in Child C cirrhosis patients regardless of the etiology of liver disease. Ghrelin levels did not correlate with liver function. Other studies have found normal ghrelin levels $(18,19,21)$. Kalaitzakis et al. (19) found that patients with cirrhosis had similar fasting ghrelin levels to a Cont group. In contrast, patients with cirrhosis had higher postprandial glucose and lower ghrelin concentrations at $4 \mathrm{~h}$ postprandially than the Cont subjects. In the study by Takahashi et al. (21), plasma ghrelin levels were slightly but not significantly elevated in patients with liver cirrhosis when compared with Cont subjects. Plasma ghrelin levels were significantly correlated with BMI, but not with the severity of liver damage. In the study by Marchesini et al. (18), ghrelin levels were not increased in cirrhosis but increased with decreasing Corli score, a method used to quatify and score the amount of ingested food, and along the scale of anorexia/hunger. In patients with primary biliary cirrhosis, Breidert et al. (22) found that serum ghrelin levels were decreased in comparison with the Cont group. We have recently found significantly decreased fasting and post-OGTT plasma ghrelin levels in patients with liver failure who were candidates for transplantation when compared with Cont subjects (24).

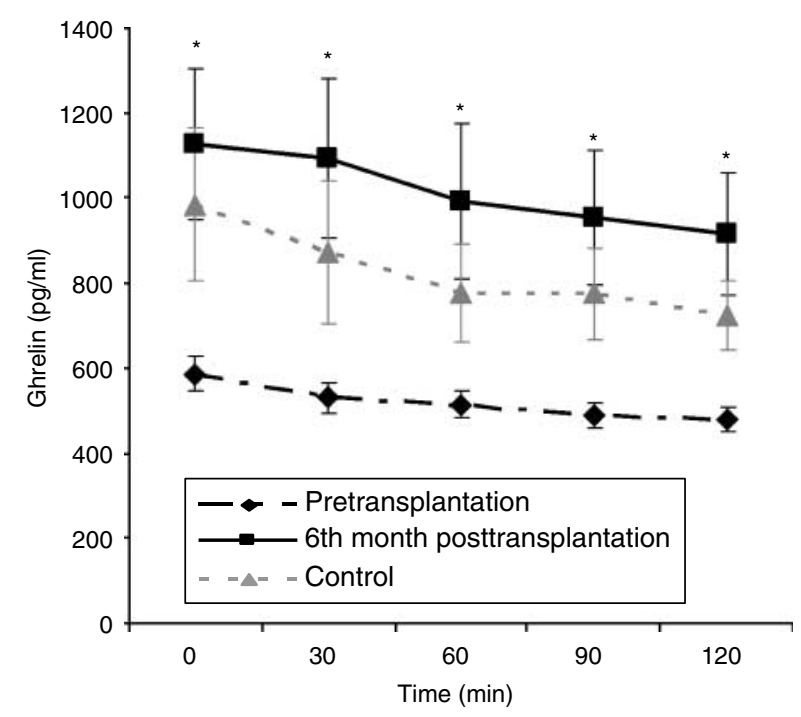

Figure 3 Mean \pm S.E.M. serum ghrelin levels $(\mathrm{pg} / \mathrm{ml})$ in controls, liver failure patients pretransplantation, and 6th month posttransplantation during the oral glucose tolerance test. ${ }^{*} P<0.05$ between controls and pretransplantation patients and $P<0.01$ between pretransplantation and 6th month posttransplantation patients. 
Discrepancies between the different studies could at least be partly explained by different patient selection, Cont subject selection, or both. The different causes of cirrhosis with a wide range of insulin sensitivity could have an impact on total ghrelin levels. Some of the patients in the different studies had a wide range of hepatocellular dysfunction, and were not BMI matched with Cont subjects. In nonalcoholic fatty liver disease, ghrelin levels have been found decreased and correlated with insulin resistance (29); in contrast with the patients with normal liver function, in the current study, the severity of liver damage was advanced. Nevertheless, both studies suggest that ghrelin levels are decreased in liver disease, although probably through different mechanisms. To our knowledge, there is only one study on postprandial ghrelin levels in liver cirrhosis. Similar to our results, the patients with cirrhosis had lower ghrelin concentrations at $4 \mathrm{~h}$ postprandially, although fasting ghrelin levels were similar to those of the Cont subjects (19). In normal subjects, there is a decrease in ghrelin levels after the OGTT (14). The response of post-OGTT ghrelin levels in hepatic failure patients was similar to normal subjects, in both groups, PreT and PostT, ghrelin levels decreased during the OGTT (24). In order to clarify the controversy over ghrelin levels in hepatic failure, we prospectively determined plasma ghrelin in liver failure patients before and after liver function normalization following transplantation. We found that decreased fasting and post-OGTT ghrelin levels in end-stage liver failure patients are normalized after liver transplantation. The response of ghrelin post-OGTT after the liver transplantation decreases in a similar way to the Cont group. This is the first study of ghrelin levels before and after liver transplantation.

The mechanisms of altered fasting or postprandial ghrelin response may involve the BMI, glucose, insulin, $\mathrm{GH}$, or all four. The concentrations of fasting ghrelin are increased in anorexia and cachexia but reduced in obesity $(10-13,30)$. Plasma ghrelin levels are negatively correlated with BMI (30). In the current study, the BMI was stable after liver transplantation, suggesting that the normalization of ghrelin levels after the transplant was not due to BMI. Insulinemia is essential for postprandial ghrelin suppression with glucose having an additional effect (31-33). Therefore, insulin resistance resulting in high postprandial glucose and insulin might be involved in the low ghrelin observed post-OGTT. A clearly negative association between ghrelin and insulin secretion has been found in humans as well as in animals by the majority of authors $(11,15,33)$, although not by all $(34,35)$. The insulin AUC correlated with the ghrelin AUC in liver failure patients before transplantation and insulin AUC decreased after the transplant, suggesting that insulin could participate in the normalization of ghrelin levels. We could not find any significant correlation between insulin and ghrelin after transplantation, probably due in part to the small number of patients, although other factors could contribute to ghrelin regulation. Ghrelin is a potent stimuli for $\mathrm{GH}$ secretion $(7,16)$ and, at least under certain physiological conditions, ghrelin modulates the regulation of GH secretion (36). Although the relationship between ghrelin and GH secretion is controversial. In acromegaly, a pathophysiological model of increased GH secretion, some studies have found normal ghrelin levels (37-40), while others have found decreased ghrelin levels in patients with acromegaly (41-43), suggesting that increased GH could contribute toward the decreased ghrelin levels, in a classic feedback manner. In liver failure patients, we found decreased IGF 1 and increased GH. After the transplant procedure, IGF1 increased and normalized, and there was a clear tendency toward a GH decrement. In the present study, fasting ghrelin negatively correlated with fasting $\mathrm{GH}$ in the 12th month after liver transplantation. In line with other studies (44), this data supports the hypothesis that GH feedback inhibits ghrelin secretion. Nevertheless, the number of patients used in the correlation studies was small, and the results of the correlation studies should be taken with great caution. Other potential confounding factors could be a drug-mediated effect, as the calcineurin inhibitor drugs (cyclosporine or tacrolimus) could decrease insulin secretion and in turn increase ghrelin, although prednisone has been found to decrease ghrelin levels (45). Alcohol is another possible confounding factor, as alcohol dependence is associated with reduced plasma ghrelin levels (46); however, our PretT patients had abstained from alcohol for 6 months. There was no difference in terms of ghrelin changes between the patients with alcoholic and nonalcoholic cirrhosis. Further studies are necessary in order to clarify the mechanism of altered ghrelin in cirrhosis. In any event, the presence of decreased fasting and post-OGTT ghrelin levels could contribute toward anorexia or other complications, in patients with advanced liver failure $(47,48)$.

In conclusion, we have found that decreased fasting and post-OGTT ghrelin levels in liver failure patients are normalized after liver transplantation.

\section{Declaration of interest}

The authors declare that there is no conflict of interest that could be perceived as prejudicing the impartiality of the research reported.

\section{Funding}

Supported in part by FIS del Instituto de Salud Carlos III PI051024, PI070413 and Red de Grupos RGTO (G03/028, PI050983) and Xunta de Galicia PS07/12, PGIDT05PXIC91605PN, INCITE08ENA916110ES and Redes 2006/27 and 2009/20, Spain.

\section{Acknowledgements}

We thank Rosa Nemiña, Ramón Pensado, Iria Brandón, and Sonia Pertega for their technical assistance. 


\section{References}

1 Selberg O, Bottcher J, Tusch G, Pichlmayr R, Henkel E \& Muller MJ. Identification of high- and low-risk patients before liver transplantation: a prospective cohort study of nutritional and metabolic parameters in 150 patients. Hepatology 199725 652-657. (doi:10.1002/hep.510250327)

2 Matos C, Porayko MK, Francisco-Ziller N \& DiCecco S. Nutrition and chronic liver disease. Journal of Clinical Gastroenterology 2002 35 391-397. (doi:10.1097/00004836-200211000-00007)

3 Lautz HU, Selberg O, Korber J, Burger M \& Muller MJ. Proteincalorie malnutrition in liver cirrhosis. Clinical Investigator 1992 70 478-486.

4 Merli M, Riggio O, Dally L \& PINC (Policentrica Italiana Nutrizione Cirrosi). Does malnutrition affect survival in cirrhosis? Hepatology 199623 1041-1046. (doi:10.1002/hep.510230516)

5 Cordido F, Penalva A, Dieguez C \& Casanueva FF. Massive growth hormone $(\mathrm{GH})$ discharge in obese subjects after the combined administration of GH-releasing hormone and GHRP-6: evidence for a marked somatotroph secretory capability in obesity. Journal of Clinical Endocrinology and Metabolism $1993 \mathbf{7 6}$ 819-823. (doi:10.1210/jc.76.4.819)

6 Alvarez-Castro P, Isidro ML, Garcia-Buela J, Leal-Cerro A, Broglio F, Tassone F, Ghigo E, Dieguez C, Casanueva FF \& Cordido F. Marked GH secretion after ghrelin alone or combined with GH-releasing hormone (GHRH) in obese patients. Clinical Endocrinology 2004 61 250-255. (doi:10.1111/j.1365-2265.2004.02092.x)

7 van der Lely AJ, Tschop M, Heiman ML \& Ghigo E. Biological, physiological, pathophysiological, and pharmacological aspects of ghrelin. Endocrine Reviews 200425 426-457. (doi:10.1210/ er.2002-0029)

8 Tschop M, Smiley DL \& Heiman ML. Ghrelin induces adiposity in rodents. Nature 2000407 908-913. (doi:10.1038/35038090)

9 Wren AM, Seal LJ, Cohen MA, Brynes AE, Frost GS, Murphy KG, Dhillo WS, Ghatei MA \& Bloom SR. Ghrelin enhances appetite and increases food intake in humans. Journal of Clinical Endocrinology and Metabolism 200186 5992. (doi:10.1210/jc.86.12.5992)

10 Cummings DE, Weigle DS, Frayo RS, Breen PA, Ma MK, Dellinger EP \& Purnell JQ. Plasma ghrelin levels after diet-induced weight loss or gastric bypass surgery. New England Journal of Medicine 2002346 1623-1630. (doi:10.1056/NEJMoa012908)

11 Tschop M, Weyer C, Tataranni PA, Devanarayan V, Ravussin E \& Heiman ML. Circulating ghrelin levels are decreased in human obesity. Diabetes 200150 707-709. (doi:10.2337/ diabetes.50.4.707)

12 Muccioli G, Tschop M, Papotti M, Deghenghi R, Heiman M \& Ghigo E. Neuroendocrine and peripheral activities of ghrelin: implications in metabolism and obesity. European Journal of Pharmacology 2002440 235-254. (doi:10.1016/S0014-2999 (02)01432-2)

13 Otto B, Cuntz U, Fruehauf E, Wawarta R, Folwaczny C, Riepl RL, Heiman ML, Lehnert P, Fichter M \& Tschop M. Weight gain decreases elevated plasma ghrelin concentrations of patients with anorexia nervosa. European Journal of Endocrinology 2001145 669-673. (doi:10.1530/eje.0.1450669)

14 Shiiya T, Nakazato M, Mizuta M, Date Y, Mondal MS, Tanaka M, Nozoe S, Hosoda H, Kangawa K \& Matsukura S. Plasma ghrelin levels in lean and obese humans and the effect of glucose on ghrelin secretion. Journal of Clinical Endocrinology and Metabolism 200287 240-244. (doi:10.1210/jc.87.1.240)

15 Cummings DE, Purnell JQ, Frayo RS, Schmidova K, Wisse BE \& Weigle DS. A preprandial rise in plasma ghrelin levels suggests a role in meal initiation in humans. Diabetes 200150 1714-1719. (doi:10.2337/diabetes.50.8.1714)

16 Kojima M \& Kangawa K. Ghrelin: structure and function. Physiological Reviews 200585 495-522. (doi:10.1152/physrev. $00012.2004)$

17 Hotta M, Ohwada R, Katakami H, Shibasaki T, Hizuka N \& Takano K. Plasma levels of intact and degraded ghrelin and their responses to glucose infusion in anorexia nervosa. Journal of Clinical Endocrinology and Metabolism 200489 5707-5712. (doi:10.1210/jc.2004-0353)

18 Marchesini G, Bianchi G, Lucidi P, Villanova N, Zoli M \& De Feo P. Plasma ghrelin concentrations, food intake, and anorexia in liver failure. Journal of Clinical Endocrinology and Metabolism 200489 2136-2141. (doi:10.1210/jc.2003-031771)

19 Kalaitzakis E, Bosaeus I, Ohman L \& Bjornsson E. Altered postprandial glucose, insulin, leptin, and ghrelin in liver cirrhosis: correlations with energy intake and resting energy expenditure. American Journal of Clinical Nutrition $2007 \mathbf{8 5} 808-815$.

20 Ataseven H, Bahcecioglu IH, Kuzu N, Yalniz M, Celebi S, Erensoy A \& Ustundag B. The levels of ghrelin, leptin, TNF-alpha, and IL-6 in liver cirrhosis and hepatocellular carcinoma due to HBV and HDV infection. Mediators of Inflammation 2006200678380. (doi:10.1155/MI/2006/78380)

21 Takahashi H, Kato A, Onodera K \& Suzuki K. Fasting plasma ghrelin levels reflect malnutrition state in patients with liver cirrhosis. Hepatology Research 200634 117-123. (doi:10.1016/ j.hepres.2005.03.019)

22 Breidert M, Zimmermann TF, Schneider R, Ehninger G \& Brabant G. Ghrelin/leptin-imbalance in patients with primary biliary cirrhosis. Experimental and Clinical Endocrinology and Diabetes 2004112 123-126. (doi:10.1055/s-2004-817819)

23 Tacke F, Brabant G, Kruck E, Horn R, Schoffski P, Hecker H, Manns MP \& Trautwein C. Ghrelin in chronic liver disease. Journal of Hepatology 200338 447-454. (doi:10.1016/S01688278(02)00438-5)

24 Diz-Lois MT, Garcia-Buela J, Suarez F, Sangiao-Alvarellos S, Vidal $\mathrm{O} \&$ Cordido F. Fasting and postprandial plasma ghrelin levels are decreased in patients with liver failure previous to liver transplantation. Endocrine 200935 467-476. (doi:10.1007/ s12020-009-9170-6)

25 Granado M, Martin AI, Lopez-Menduina M, Lopez-Calderon A \& Villanua MA. GH-releasing peptide-2 administration prevents liver inflammatory response in endotoxemia. American Journal of Physiology. Endocrinology and Metabolism 2008294 E131-E141. (doi:10.1152/ajpendo.00308.2007)

26 Iseri SO, Sener G, Saglam B, Ercan F, Gedik N \& Yegen BC. Ghrelin alleviates biliary obstruction-induced chronic hepatic injury in rats. Regulatory Peptides 2008146 73-79. (doi:10.1016/j.regpep. 2007.08.014)

27 Kasimay O, Iseri SO, Barlas A, Bangir D, Yegen C, Arbak S \& Yegen BC. Ghrelin ameliorates pancreaticobiliary inflammation and associated remote organ injury in rats. Hepatology Research 200636 11-19. (doi:10.1016/j.hepres.2006.06.009)

28 Matthews DR, Hosker JP, Rudenski AS, Naylor BA, Treacher DF \& Turner RC. Homeostasis model assessment: insulin resistance and beta-cell function from fasting plasma glucose and insulin concentrations in man. Diabetologia 198528 412-419. (doi:10. 1007/BF00280883)

29 Marchesini G, Pagotto U, Bugianesi E, De Iasio R, Manini R, Vanni E, Pasquali R, Melchionda N \& Rizzetto M. Low ghrelin concentrations in nonalcoholic fatty liver disease are related to insulin resistance. Journal of Clinical Endocrinology and Metabolism 200388 5674-5679. (doi:10.1210/jc.2003-031094)

30 Haqq AM, Farooqi IS, O'Rahilly S, Stadler DD, Rosenfeld RG, Pratt KL, LaFranchi SH \& Purnell JQ. Serum ghrelin levels are inversely correlated with body mass index, age, and insulin concentrations in normal children and are markedly increased in Prader-Willi syndrome. Journal of Clinical Endocrinology and Metabolism 200388 174-178. (doi:10.1210/jc.2002-021052)

31 Murdolo G, Lucidi P, Di Loreto C, Parlanti N, De Cicco A, Fatone C, Fanelli CG, Bolli GB, Santeusanio F \& De Feo P. Insulin is required for prandial ghrelin suppression in humans. Diabetes $2003 \mathbf{5 2}$ 2923-2927. (doi:10.2337/diabetes.52.12.2923)

32 Flanagan DE, Evans ML, Monsod TP, Rife F, Heptulla RA, Tamborlane WV \& Sherwin RS. The influence of insulin on circulating ghrelin. American Journal of Physiology. Endocrinology and Metabolism 2003284 E313-E316. 
33 Blom WA, Stafleu A, de Graaf C, Kok FJ, Schaafsma G \& Hendriks HF. Ghrelin response to carbohydrate-enriched breakfast is related to insulin. American Journal of Clinical Nutrition 200581 $367-375$.

34 Caixas A, Bashore C, Nash W, Pi-Sunyer F \& Laferrere B. Insulin, unlike food intake, does not suppress ghrelin in human subjects. Journal of Clinical Endocrinology and Metabolism 2002871902. (doi:10.1210/jc.87.4.1902)

35 Schaller G, Schmidt A, Pleiner J, Woloszczuk W, Wolzt M \& Luger A. Plasma ghrelin concentrations are not regulated by glucose or insulin: a double-blind, placebo-controlled crossover clamp study. Diabetes 200352 16-20. (doi:10.2337/diabetes. 52. 1.16)

36 Nass R, Farhy LS, Liu J, Prudom CE, Johnson ML, Veldhuis P, Pezzoli SS, Oliveri MC, Gaylinn BD, Geysen HM \& Thorner MO. Evidence for acyl-ghrelin modulation of growth hormone release in the fed state. Journal of Clinical Endocrinology and Metabolism 200893 1988-1994. (doi:10.1210/jc.2007-2234)

37 van der Toorn FM, Janssen JA, de Herder WW, Broglio F, Ghigo E \& van der Lely AJ. Central ghrelin production does not substantially contribute to systemic ghrelin concentrations: a study in two subjects with active acromegaly. European Journal of Endocrinology 2002147 195-199. (doi:10.1530/eje.0.1470195)

38 Barkan AL, Dimaraki EV, Jessup SK, Symons KV, Ermolenko M \& Jaffe CA. Ghrelin secretion in humans is sexually dimorphic, suppressed by somatostatin, and not affected by the ambient growth hormone levels. Journal of Clinical Endocrinology and Metabolism 2003 88 2180-2184. (doi:10.1210/jc.2002-021169)

39 Jarkovska Z, Rosicka M, Marek J, Hana V, Weiss V, Justova V, Lacinova Z, Haluzik M \& Krsek M. Plasma levels of total and active ghrelin in acromegaly and growth hormone deficiency. Physiological Research 200655 175-181.

40 Isidro ML, Nemina R, Garcia-Buela J, Sangiao-Alvarellos S \& Cordido F. Effect of oral glucose on acylated and total ghrelin secretion in acromegalic patients. Neuro Endocrinology Letters 200728 596-603.

41 Cappiello V, Ronchi C, Morpurgo PS, Epaminonda P, Arosio M, Beck-Peccoz P \& Spada A. Circulating ghrelin levels in basal conditions and during glucose tolerance test in acromegalic patients. European Journal of Endocrinology 2002147 189-194. (doi:10.1530/eje.0.1470189)

42 Freda PU, Reyes CM, Conwell IM, Sundeen RE \& Wardlaw SL. Serum ghrelin levels in acromegaly: effects of surgical and long-acting octreotide therapy. Journal of Clinical Endocrinology and Metabolism 200388 2037-2044. (doi:10.1210/jc.2002-021683)

43 Kozakowski J, Rabijewski M \& Zgliczynski W. Decrease in serum ghrelin levels in patients with acromegaly normalize after successful surgical treatment. Endokrynologia Polska 200556 $862-870$.

44 Vestergaard ET, Dall R, Lange KH, Kjaer M, Christiansen JS \& Jorgensen JO. The ghrelin response to exercise before and after growth hormone administration. Journal of Clinical Endocrinology and Metabolism 200792 297-303. (doi:10.1210/jc.2006-1435)

45 Otto B, Tschop M, Heldwein W, Pfeiffer AF \& Diederich S. Endogenous and exogenous glucocorticoids decrease plasma ghrelin in humans. European Journal of Endocrinology 2004151 113-117. (doi:10.1530/eje.0.1510113)

46 Badaoui A, De Saeger C, Duchemin J, Gihousse D, de Timary P \& Starkel P. Alcohol dependence is associated with reduced plasma and fundic ghrelin levels. European Journal of Clinical Investigation 200838 397-403. (doi:10.1111/j.1365-2362.2008.01947.x)

47 Moreno M, Chaves JF, Sancho-Bru P, Ramalho F, Ramalho LN, Mansego ML, Ivorra C, Dominguez M, Conde L, Millan C, Mari M, Colmenero J, Lozano JJ, Jares P, Vidal J, Forns X, Arroyo V, Caballeria J, Gines P \& Bataller R. Ghrelin attenuates hepatocellular injury and liver fibrogenesis in rodents and influences fibrosis progression in humans. Hepatology 201051 974-985. (doi:10.1002/hep.23421)

48 Kalaitzakis E, Sadik R, Holst JJ, Ohman L \& Bjornsson E. Gut transit is associated with gastrointestinal symptoms and gut hormone profile in patients with cirrhosis. Clinical Gastroenterology and Hepatology 20097 346-352. (doi:10.1016/j.cgh.2008.11.022)

Received 16 June 2010

Accepted 7 July 2010 